\title{
Small bowel adenocarcinoma phenotyping, a clinicobiological prognostic study
}

\begin{abstract}
T Aparicio ${ }^{*}, 1$, M Surcek ${ }^{2}$, A Zaanan ${ }^{3,4}$, E Beohou ${ }^{5}$, A Laforest ${ }^{4}$, P Afchain ${ }^{6}$, Emmanuel Mitry ${ }^{7}$, J Taieb $^{3}$, F Di Fiore $^{8}$, J-M Gornet ${ }^{9}$, A Thirot-Bidault ${ }^{10}$, I Sobhani ${ }^{11}$, D Malka ${ }^{12}$, T Lecomte $^{13}$, C Locher $^{14}$, F Bonnetain ${ }^{5}$ and P Laurent-Puig ${ }^{4}$

${ }^{1}$ Gastroenterology and Digestive Oncology, APHP, Hôpitaux Universitaires de Seine Saint Denis, Avicenne Hospital, University Paris 13, Paris Sorbonne Cité, 125 rue de Stalingrad, Bobigny 93000, France; ${ }^{2}$ Pathology, APHP, Groupement Universitaire Est Parisien, Saint Antoine Hospital, 184 rue du Faubourg Saint Antoine, Paris 75012, France; ${ }^{3}$ Gastroenterology and Digestive Oncology, APHP, Georges Pompidou Hospital, University Paris Descartes, 20 rue Leblanc, Paris 75015, France; ${ }^{4}$ INSERM UMR-S775 Bases Moléculaires de la Réponse aux Xénobiotiques, Paris Sorbonne Cité, 45 rue des Saint Père, Paris 75006, France; ${ }^{5}$ Methodology and Quality of Life unit in oncology, EA 3181, University Hospital, 3 Boulevard Alexandre Fleming, Besançon 25000, France; ${ }^{6}$ Oncology, APHP, Groupement Universitaire Est Parisien, Saint Antoine Hospital, 184 rue du Faubourg Saint Antoine, 75012, Paris, France; ${ }^{7}$ Institut Curie, Ensemble hospitalier et Université Versailles St-Quentin, 26 rue d'Ulm, Paris 75005, France; ${ }^{8}$ Gastroenterology, CHU Charles Nicole, rue de Germont, Rouen 76031, France; '9astroenterology, CHU Saint-Louis, APHP, 1, Avenue Claude-Vellefaux, Paris 75010, France; ${ }^{10}$ Gastroenterology, CHU Kremlin Bicêtre, APHP, 78 Rue du Général Leclerc, Kremlin Bicêtre 94275, France; ${ }^{11}$ Gastroenterology, APHP, Henri Mondor hospital, University Paris-Est Créteil, 51 Avenue du Maréchal de Lattre de Tassigny, Créteil 94010, France; ${ }^{12}$ Gastroenterology, Institut Gustave Roussy, 114, rue Édouard-Vaillant, Villejuif 94805, France; ${ }^{13}$ Gastroenterology, CHU Tours, 2 Boulevard Tonnellé, Tours 37000, France and ${ }^{14}$ Gastroenterology, CH Meaux, 6-8, rue Saint-Fiacre, Meaux 77104, France
\end{abstract}

Background: Small bowel adenocarcinoma (SBA) is a rare tumour with a poor prognosis. Molecular biology data on SBA carcinogenesis are lacking.

Methods: Expression of HER2, $\beta$-catenin, p53 and mismatch repair (MMR) protein was assessed by immunohistochemistry. KRAS, V600E BRAF mutations and microsatellite instability were investigated.

Results: We obtained samples from 63 SBA patients (tumour stages: I-II: 30\%; III: 35\%; IV: 32\%; locally advanced: 3\%). HER2 overexpression ( $3+$ ) was observed in 2 out of 62 patients, overexpression of p53 in 26 out of 62 , abnormal expression of $\beta$-catenin in 12 out of 61, KRAS mutation in 21 out of 49, BRAF V600E mutation in 1 out of 40 patients, MMR deficiency (dMMR) in 14 out of 61 and was consistent with Lynch syndrome in 9 out of 14 patients. All of the dMMR tumours were in the duodenum or jejunum and only one was stage IV. Median overall survival (OS) was 36.6 months $(95 \% \mathrm{Cl}, 26.9-72.2)$. For all patients, in univariate analysis, stages I-II $(P<0.001)$, WHO PS 0-1 $(P=0.01)$ and dMMR phenotype $(P=0.02)$ were significantly associated with longer OS. In multivariate analysis, disease stage $(P=0.01)$ and WHO PS 0-1 $(P=0.001)$ independently predicted longer OS. For stage IV patients, median OS was 20.5 months (95\% Cl: 14.6; 36.6 months). In multivariate analysis, WHO PS 0-1 ( $P=0.0001)$ and mutated KRAS status $(P=0.02)$ independently predicted longer OS.

Conclusion: This large study suggests that molecular alterations in SBA are closer to those in colorectal cancer (CRC) than those in gastric cancer, with low levels of HER 2 overexpression and high frequencies of KRAS mutations. The seemingly higher frequency of dMMR than in CRC may be explained by the higher frequency of Lynch syndrome in SBA patients. A dMMR phenotype was significantly associated with a non-metastatic tumour $(P=0.02)$. A trend for a good prognosis and a duodenum or jejunum primary site was associated with dMMR.

\footnotetext{
*Correspondence: Professor T Aparicio; E-mail: thomas.aparicio@avc.aphp.fr

This work has been presented at the Journées Francophones d'Hépato-gastroentérologie et d'Oncologie Digestive (JFHOD) in 2013, at the ASCO annual meeting in 2013 and partially at the ESMO meeting in 2012.
}

Received 9 August 2013; revised 1 October 2013; accepted 3 October 2013; published online 5 November 2013

(c) 2013 Cancer Research UK. All rights reserved 0007-0920/13 
Although the small intestine accounts for $75 \%$ of the length of the digestive tract and $90 \%$ of the mucosal surface area, small bowel cancers are rare: $<5 \%$ of gastrointestinal cancers (Neugut et al, 1998). Small bowel adenocarcinoma (SBA) represents around 40\% of small bowel cancers (Lepage et al, 2006; Bilimoria et al, 2009), with roughly the same incidence as neuroendocrine tumours. In the United States of America, the estimated incidence of SBA is 5300 new cases per year, with around 1100 deaths per year (Kummar et al, 2002). The EUROCARE data indicate an estimated 3595 new cases of SBA every year in Europe (Faivre et al, 2012). The duodenum is most frequently involved, followed by the jejunum and ileum (Lepage et al, 2006; Bilimoria et al, 2009; Aparicio et al, 2013a).

SBA carries a poor prognosis at all stages with a 5-year overall survival (OS) of $50-60 \%$ for stage I, $39-55 \%$ for stage II, $10-40 \%$ for stage III and 3-5\% for stage IV (Talamonti et al, 2002; Dabaja et al, 2004; Overman et al, 2012). So, the prognosis of SBA appears to be intermediary between those of colon and gastric cancer. Lymph node metastases are the main prognostic factor (Talamonti et al, 2002; Dabaja et al, 2004). There is no evidence to support the use of adjuvant chemotherapy in SBA, but it may improve prognosis in cases of invaded lymph nodes (Overman et al, 2010b). In advanced disease, oxaliplatin-based chemotherapy appears to give the best results, with a median OS of 17.8 months (Zaanan et al, 2010).

Biological parameters have been studied in few SBA patients (Aparicio et al, 2013c), and some results are conflicting. Moreover, the prognostic value of biological factors or of differences in tumour phenotype according to the primary site has never been assessed in SBA in a large number of patients together with the main changes in biological alteration. The aim of this study was to investigate several candidate genes or their protein expression in the genetic pathway of SBA.

The $A P C$ gene acquires a truncated mutation in the majority of sporadic colorectal cancers (CRCs) and is also responsible for familial adenomatous polyposis in cases of germline mutation. The inactivation of APC protein leads to an accumulation of $\beta$-catenin in the nuclei. More rarely, the $\beta$-CATENIN gene acquires a gain-of-function mutation. These augmentations of $\beta$-catenin activity in both cases lead to increased proliferation of epithelial cells and are considered an early event in the majority of CRCs (Behrens, 2005).

$\mathrm{P} 53$ is a nuclear oncosuppressor protein that is involved in the maintenance of genomic integrity. Mutations in the p53 gene occur commonly in a wide range of cancers and result in overexpression of inactive p53 protein in the nuclei. P53 mutations are a late event in colorectal carcinogenesis (Ilyas et al, 1999).

The KRAS gene codes for a GTPase involved in the signalling pathways of several tyrosine kinase receptors. A KRAS mutation has been described in around $40 \%$ of CRCs, mainly in codons 12 or 13 . Moreover, KRAS mutations are predictive of the lack of efficacy of anti-EGFR antibody in treatment of metastatic CRC (Lievre et al, 2008).

HER2 is one of a family of human epidermal growth factor receptors (HERs). Gene amplification and overexpression of HER$2 /$ neu have been reported in around $15 \%$ of gastric cancers. Treatment with trastuzumab, an anti-HER-2 antibody, results in prolonged survival in gastric cancer if HER-2 is overexpressed or amplified in tumour cells (Bang et al, 2010).

Inactivation of the DNA mismatch repair (MMR) gene is characterised by tumour microsatellite instability (Zaanan et al, 2011b). Four MMR genes have been described-MLH1, MSH2, MSH6 and PMS2 - and could be mutated, resulting in the loss of protein expression assessed by immunohistochemistry (Hampel et al, 2005). The germline mutation of one of the MMR genes is responsible for Lynch syndrome and predisposes to SBA (Bonadona et al, 2011). Loss of MLH1 protein function could also result from hypermethylation of the $M L H 1$ promoter and accounts for $>20 \%$ of cases of CRC in elderly patients (Aparicio et al, 2013b). A BRAF V600 E mutation is frequently associated with MLH1 promoter methylation in sporadic colorectal carcinomas (Koinuma et al, 2004).

We characterised the protein and/or gene expression of $\beta$-catenin, p53, HER-2, MMR, KRAS and BRAF in a large number of SBA tumours. We investigated their expression according to the small bowel segment and defined the prognostic value of each. The results of this large study have direct clinical implications as some of the proteins/genes investigated are potential therapeutic targets.

\section{PATIENTS AND METHODS}

Study population and tumour samples. A previous AGEO study (Zaanan et al, 2010; Zaanan et al, 2011a) identified a series of 154 consecutive patients treated for SBA in 13 hospitals from 1996 to 2008. Among these patients, 91 were excluded because tumour samples were unavailable, mainly because of an unresectable or metastatic tumour or because no biopsy sample remained. A total of 63 cases from 12 hospitals were included and reviewed by a gastrointestinal pathologist (MS) to confirm the diagnosis and tumour grade. The clinical and follow-up data were partially collected in the previous AGEO studies and completed for the purpose of the present study. Data include demographics, cancer treatment history, stage, lymph node invasion, tumour differentiation, predisposing disease or known genetic syndrome, recurrence and survival. Patients were enrolled in the study at all stages of the disease, but tumour samples in all cases were from the primary tumour.

This study was authorised by the ethics committee 'Ile de France II' No. ID-RCB: 2008-A01058-47.

Immunohistochemical analysis. Briefly, $4-\mu \mathrm{m}$ sections from the paraffin-embedded tissue samples were cut onto silane-treated Super Frost slides (CML, Nemours, France) and left to dry at $37^{\circ} \mathrm{C}$ overnight. The slides were deparaffinised in xylene and rehydrated in pure ethanol. Endogenous peroxidase was blocked using 3\% hydrogen peroxide in methanol for $30 \mathrm{~min}$. Before immunostaining, antigen retrieval was performed by immersing sections in citrate buffer ( $\mathrm{pH}$ 6.0). Sections were then incubated for $15 \mathrm{~min}$ at room temperature with antibodies to MLH1 (dilution 1/70, clone G168-728, Pharmingen, San Diego, CA, USA), MSH2 (dilution 1/100, clone FE11, Calbiochem, Oncogene Research Products, Cambridge, MA, USA), MSH6 (dilution 1/100, clone 44, Becton Dickinson, Lexington, NC, USA), PMS2 (clone A16-4, $1: 150$ dilution, BD PharMingen, Le Pont de Claix, France), $\beta$-catenin (E-5; 1/250 dilution; Santa Cruz Biotechnology, Santa Cruz, CA, USA) and p53 (clone BP53-12-1; 1/800 dilution; Biogenex, San Ramon, CA, USA). The Bond Polymer Refine Detection kit (Leica, Nanterre, France) was used as the detection system. Immunostaining of MLH1, MSH2, MSH6 and PMS2 in tumour cells was evaluated as positive or negative. Tumours were considered negative when there was a complete absence of nuclear staining of neoplastic cells in the presence of an internal positive control. Tumours were classified as p53-positive when $>50 \%$ of nuclei in the carcinomatous epithelium were immunostained, as previously described (Samowitz et al, 2002). For $\beta$-catenin, nuclear staining was evaluated as present or absent, separately for each specimen (Zhang et al, 2006). Nuclear accumulation of $\beta$-catenin was considered to reflect Wnt pathway activation. The expression of HER2 was investigated by immunochemistry using the antibody A0485 (DAKO, Trappes, France; 1:500 dilution).

Fluorescent in situ hybridisation:. Tumours overexpressing HER2 protein as noted by immunohistochemistry (score $3+$ ) 
were tested by fluorescent in situ hybridisation (FISH) performed using the pharmDxTM test kit (Dako Denmark A/S, Glostrup, Denmark). An HER2:CEP17 ratio $\geqslant 2$ was taken to indicate amplification.

Determination of $M L H 1$ promoter methylation:. The DNA methylation pattern of the $M L H 1$ promoter region was determined by methylation-specific PCR on bisulphite-treated DNA $(1 \mu \mathrm{g})$ with primer sequences used by Park et al (2003). This technique was performed in cases of loss of MLH1 protein expression.

Molecular analysis. DNA was extracted from formalin-fixed paraffin-embedded samples. The seven most frequent mutations on codons 12 and 13 of KRAS were assessed as previously described (Lievre et al, 2008). BRAF V600E mutations were detected by allelic discrimination using TaqMan probes following the same protocol as for KRAS mutations. Probes and protocol are available on request. MSI status was assessed using five microsatellites (BAT25, BAT26, NR21, NR24, NR27), and the deficient MMR phenotype was assigned if $\geqslant 2$ microsatellites were unstable.

Statistical analysis. For demographic and clinical characteristics, categorical variables were summarised as frequency and percentage and continuous variables as mean and s.d. Tumour characteristics were analysed according to tumour stage and primary site. The link between variables was assessed using the Fisher's exact test or the $\chi^{2}$ test, as appropriate.

OS was defined as the time from diagnosis (diagnosis of metastases in subgroup analysis for metastatic patients) to death by any cause. Recurrence-free survival (RFS) was defined as the time from surgery to first recurrence (local or distant) or death (from any cause). Patients alive at the date cutoff without recurrence were censored. OS and RFS were estimated using the Kaplan-Meier method and described by the median with its 95\% confidence interval (CI). Survival curves were compared using the log-rank test. Median follow-up was calculated with the reverse KaplanMeier method.

All analyses were first performed among the whole population, then in stage I-III patients and finally among metastatic patients.

Univariate proportional hazards Cox models were used to estimate hazard ratio (HR) with its $95 \% \mathrm{CI}$ and to select potential prognostic factors linked to different end points. Proportional hazards assumptions were tested using the Schoenfeld residuals. All significant variables observed in univariate analysis at a $10 \%$ level were included in multivariate analysis. A ratio of at least 10 events per variable was recommended for the development of a stable model.

From the final multivariate model, we computed the Akaike information criterion for goodness of fit and Harrell's C-statistic for discrimination (a Harrell's $\mathrm{C}$ index of 0.5 indicates no predictive discrimination and a Harrell's $\mathrm{C}$ index of 1.0 indicates perfect separation of patients).

All analyses were conducted with a two-sided $\alpha$ level of $5 \%$, and data were analysed by using R software, Version 2.15.1 (www.r-project.org/?).

\section{RESULTS}

Clinicopathological characteristics of the patients. Sixty-three patients were enrolled in the study. Patient and tumour characteristics are summarised in Table 1. Ages of patients ranged from 29 to 85 years, with a median of 58 years.

All patients with stages I to III tumours underwent resection surgery. For the 19 patients with a stage I-II tumour, 9 (47\%) had 1-7 lymph nodes assessed and 10 (53\%) had $>7$ lymph nodes assessed. For the 22 patients with a stage III tumour, $11(50 \%)$ had $1-2$ positive lymph nodes and $11(50 \%)$ had $\geqslant 3$ positive lymph
Table 1. Patient and tumour characteristics

Characteristic

No. (\%) of

patients $(n=63)$

Sex

\begin{tabular}{|l|l}
\hline Men & $33(52)$
\end{tabular}

\begin{tabular}{l|l} 
Women & $30(48)$
\end{tabular}

\begin{tabular}{|l|l}
\hline Predisposing disease & $17(27)$
\end{tabular}

\begin{tabular}{l|l} 
Crohn's disease & $8(12)$
\end{tabular}

Lynch syndrome 6 (9)

Familial adenomatous polyposis 2 (3)

Coeliac disease

2 (3)

Tumour stage at diagnosis

\begin{tabular}{|l|l}
\hline I-II & $19(30)$
\end{tabular}

III $22(35)$

IV 20 (32)

Locally advanced

2 (3)

Primary tumour site

\begin{tabular}{l|l}
\hline Duodenum & $32(51)$ \\
Jejunum & $18(29)$ \\
lleum & $13(20)$
\end{tabular}

Histological grade

Well differentiated

Moderately differentiated

Poorly differentiated

27 (43)

$23(36)$

$13(21)$

nodes. Among these 22 patients, 3 had an R1 or R2 resection. Among the 19 patients with an R0 resected stage III tumour, adjuvant chemotherapy was performed in 16 (84\%) cases.

Palliative chemotherapy was performed in 43 patients (20 stage IV with synchronous metastases, 2 locally advanced unresectable tumours and 21 metachronous metastases). The first-line chemotherapy prescribed was 5-fluoruracil $(5 \mathrm{FU})+$ oxaliplatin in $23(53 \%), 5 \mathrm{FU}+$ irinotecan in $7(16 \%), 5 \mathrm{FU}+$ cisplatin in $5(12 \%)$, $5 \mathrm{FU}$ monotherapy in $4(9 \%), 5 \mathrm{FU}+$ irinotecan + bevacizumab in $3(7 \%)$ and capecitabine in $1(2 \%)$.

Tumour phenotyping. Sixty-three tumours were available for analysis. In some tumours, all the immunochemistry analyses were not conclusive. For molecular analysis, only a part of the population could be analysed due to tumour fixation in picric acid in 14 cases.

P53 expression was assessed in 62 cases. Overexpression was present in $26(42 \%)$ of the cases (Figure 1A). There is no interaction between differentiation grade and p53 overexpression as 12 out of $27(44 \%)$ of the well-differentiated tumours and 6 out of $13(46 \%)$ of the poorly differentiated had an overexpression of p53. Only 2 out of 14 (14\%) of dMMR tumours showed p53 overexpression.

$\beta$-Catenin expression was assessed in 61 cases. Nuclear staining for $\beta$-catenin was noted in $12(20 \%)$ tumours (Figure $1 \mathrm{~B}$ and $\mathrm{C}$ ).

HER2 expression was assessed in 62 cases. Overexpression of HER $(3+)$ was observed in two ileum tumours (3.2\%) (Figure 1D). These two tumours were FISH-positive.

Tumour MMR status was determined by molecular analysis or immunohistochemistry (IHC). Defective MMR (dMMR) phenotype was defined as the presence of either high-level tumour DNA MSI (MSI-H) or as the loss of tumour MLH1, MSH2, MSH6 or PMS2 protein expression. Proficient MMR (pMMR) phenotype 
a

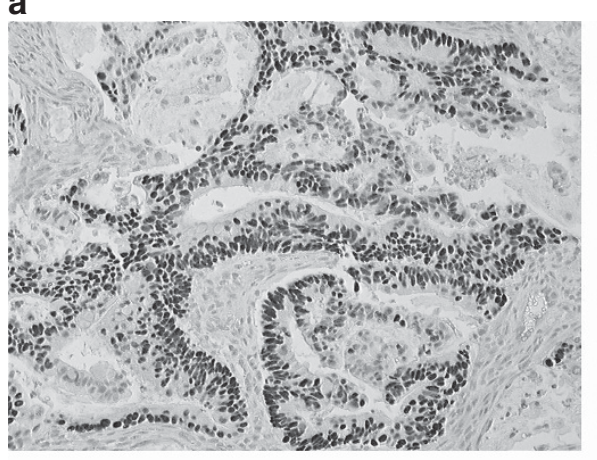

c

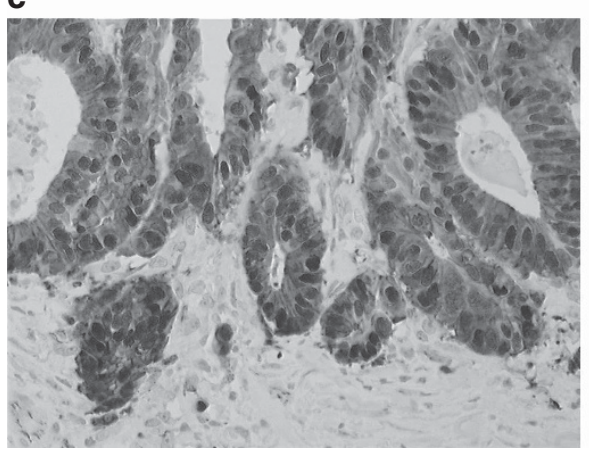

b

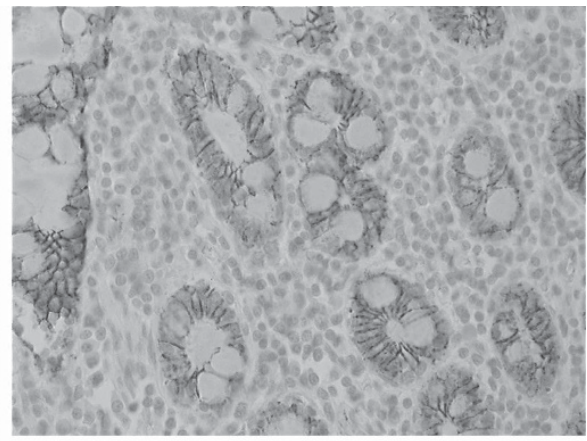

d

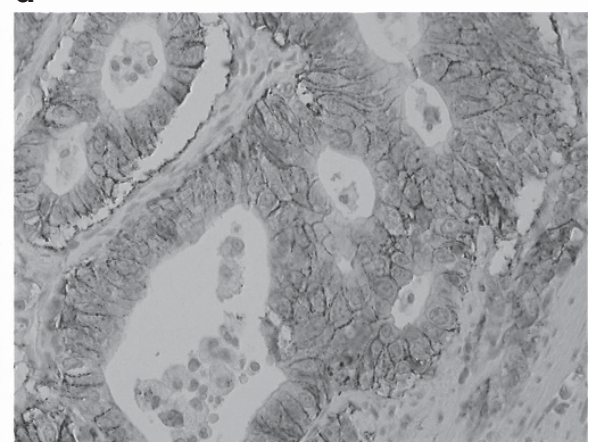

Figure 1. Representative immunohistochemical staining. (A) Positive p53 immunostaining ( $\times 200$ magnification); (B) in normal small intestinal epithelium, $\beta$-catenin was expressed exclusively on the plasma membrane, with no nuclear positivity ( $\times 400$ magnification); (C) tumour cells with aberrant nuclear staining of $\beta$-catenin ( $\times 400$ magnification); and (D) tumour cells strongly expressing HER2 (scoring $3+$ ) ( $\times 400$ magnification). Amplification of HER2 was observed in this case.

was defined by tumour DNA microsatellite stable status, low-level MSI (MSI-L) status or normal tumour MLH1, MSH2, MSH6 or PMS2 protein expression. The MMR phenotype was assessed by molecular analysis in 42 cases and by IHC in 51 cases (with expression of all four proteins analysable). Altogether MMR status was determined in 61 patients by one or two methods. No discordance between IHC and molecular analysis assays was observed. A dMMR phenotype was observed in 14 (23\%) of the tumours. The median age of patients was 58 years in those with dMMR tumours and 57 years in those with pMMR tumours. In 8 of these 14 tumours, expression of at least one MMR protein was deficient. Four tumours had a concomitant loss of expression of MLH1 and PMS2, two tumours had a concomitant loss of expression of MSH2 and MSH6 and two tumours had a loss of expression of MSH6. Among the four tumours with loss of MLH1 expression, $M L H 1$ promoter methylation was determined in three. One of them had methylation of the MLH1 promoter and was classified as likely sporadic. Two did not present any methylation of the promoter: one corresponded to Lynch syndrome and the other to a lack of history of familial cancer. The remaining six cases of dMMR tumours were identified by molecular analysis. Altogether, Lynch syndrome was suspected in 9 out of $14(64 \%)$ patients with a dMMR tumour according to their family history or to MSH2 or MSH6 loss of expression. In the 52 remaining patients with sporadic tumours, dMMR tumours were seen in 5 (9.6\%).

KRAS mutation was assessed in 49 patients. A mutation was founded in $21(43 \%)$ of the tumours. The KRAS mutation involved codon 12 in $12(57 \%)$ of the mutated cases, codon 13 in $6(29 \%)$, codon 61 in $2(10 \%)$ and codon 146 in one (5\%). A BRAF V600E mutation was assessed in 40 patients. Only one tumour was mutated: this tumour had no KRAS mutation and a pMMR phenotype.

Tumour characteristics according to tumour stage. Tumour phenotype was analysed according to stage in univariate analysis.

\begin{tabular}{|c|c|c|c|c|}
\hline $\begin{array}{l}\text { Tumour } \\
\text { characteristic }\end{array}$ & $\begin{array}{c}\text { Stages I-II, } \\
n=19 \\
(30 \%)\end{array}$ & $\begin{array}{c}\text { Stage III, } \\
n=22 \\
(35 \%)\end{array}$ & $\begin{array}{c}\text { Stage IV } \\
n=20 \\
(32 \%)\end{array}$ & $\boldsymbol{P}$ value \\
\hline $\begin{array}{l}\text { Poorly differentiated } \\
(n=13)\end{array}$ & $1(8 \%)$ & $6(46 \%)$ & $6(46 \%)$ & 0.10 \\
\hline $\begin{array}{l}\text { P53 overexpression } \\
(n=26)\end{array}$ & $14(54 \%)$ & $3(11 \%)$ & 9 (35\%) & $<0.001$ \\
\hline $\begin{array}{l}\text { Abnormal } \beta \text {-catenin } \\
(n=12)\end{array}$ & $5(42 \%)$ & $3(25 \%)$ & $4(33 \%)$ & 0.61 \\
\hline $\begin{array}{l}\text { dMMR phenotype } \\
(n=14)\end{array}$ & $4(29 \%)$ & $9(64 \%)$ & $1(7 \%)$ & 0.02 \\
\hline Mutated KRAS $\left(n=21^{\mathrm{a}}\right)$ & $5(24 \%)$ & $8(38 \%)$ & 7 (33\%) & 0.79 \\
\hline
\end{tabular}

A dMMR phenotype was significantly associated with a non-metastatic tumour $(P=0.02)$ (Table 2$)$. P53 overexpression varied significantly according to tumour stage.

Tumour characteristics according to primary site. Tumour characteristics were analysed according to the primary site (Table 3). A dMMR phenotype was observed in $28 \%$ of tumours in both duodenum (9 out of 32) and jejunum (5 out of 32) and none in the ileum. Among the 13 tumours in the ileum, Crohn's disease was reported in $6(46 \%)$ cases. The only two cases of tumours with HER2 overexpression were located in the ileum.

\section{Survival analysis}

Overall survival for all patients. The median follow-up was 72.7 months (95\% CI: 59.2; 113.2 months). There were 39 deaths at the 


\begin{tabular}{|c|c|c|c|c|}
\hline $\begin{array}{l}\text { Tumour } \\
\text { characteristic }\end{array}$ & $\begin{array}{c}\text { Duodenum, } \\
\begin{array}{c}n=32 \\
(51 \%)\end{array}\end{array}$ & $\begin{array}{c}\text { Jejunum, } \\
\begin{array}{c}n=18 \\
(29 \%)\end{array}\end{array}$ & $\begin{array}{l}\text { lleum, } \\
n=13 \\
(20 \%)\end{array}$ & $P$-value \\
\hline Stages I-II $(n=19)$ & $8(42 \%)$ & 7 (37\%) & $4(21 \%)$ & \\
\hline Stage III $(n=22)$ & 13 (59\%) & $5(23 \%)$ & $4(18 \%)$ & 0.81 \\
\hline Stage IV $(n=20)$ & $9(45 \%)$ & $6(30 \%)$ & $5(25 \%)$ & \\
\hline $\begin{array}{l}\text { Poorly differentiated } \\
(n=13)\end{array}$ & $5(38 \%)$ & $3(24 \%)$ & $5(38 \%)$ & 0.23 \\
\hline $\begin{array}{l}\text { P53 overexpression } \\
(n=26)\end{array}$ & $13(50 \%)$ & $8(31 \%)$ & $5(19 \%)$ & 0.89 \\
\hline $\begin{array}{l}\text { Abnormal } \beta \text {-catenin } \\
(n=12)\end{array}$ & $4(33 \%)$ & $3(25 \%)$ & $5(42 \%)$ & 0.16 \\
\hline $\begin{array}{l}\text { dMMR phenotype } \\
(n=14)\end{array}$ & $9(64 \%)$ & $5(36 \%)$ & $0(0 \%)$ & 0.07 \\
\hline $\begin{array}{l}\text { Mutated KRAS } \\
(n=21)\end{array}$ & 12 (57\%) & $6(29 \%)$ & $3(14 \%)$ & 0.73 \\
\hline $\begin{array}{l}\text { HER2 expression } \\
2+(n=2)\end{array}$ & $0(0 \%)$ & $0(0 \%)$ & 2 (100\%) & - \\
\hline
\end{tabular}

Table 4. Prognostic factors according to overall survival in all patients

\begin{tabular}{|c|c|c|c|c|}
\hline & \multicolumn{4}{|c|}{ Univariate analyses } \\
\hline & \multicolumn{4}{|c|}{$\begin{array}{c}\text { Overall survival } \\
\text { (all patients } n=61 \text { ) }\end{array}$} \\
\hline & Evts/pts & HR & $95 \% \mathrm{Cl}$ & $\boldsymbol{P}$-value ${ }^{a}$ \\
\hline \multicolumn{5}{|l|}{ Sex } \\
\hline Male vs female & $39 / 61$ & 1.19 & $0.62-2.30$ & 0.61 \\
\hline \multicolumn{5}{|l|}{ Age in years } \\
\hline $\begin{array}{l}\text { Continuous } \\
>65 \text { vs } \leqslant 65\end{array}$ & $\begin{array}{l}39 / 61 \\
39 / 61\end{array}$ & $\begin{array}{l}0.98 \\
0.65\end{array}$ & $\begin{array}{l}0.96-1.00 \\
0.32-1.32\end{array}$ & $\begin{array}{l}0.06 \\
0.23\end{array}$ \\
\hline \multicolumn{5}{|l|}{ WHO PS } \\
\hline 2 vs $0-1$ & $32 / 38$ & 3.4 & $1.47-7.97$ & $<0.01$ \\
\hline \multicolumn{5}{|l|}{ Disease stage } \\
\hline $\begin{array}{l}\text { Stage III vs stages I and II } \\
\text { Stage IV vs stages I and II }\end{array}$ & $\begin{array}{l}37 / 59 \\
37 / 59\end{array}$ & $\begin{array}{l}1.20 \\
6.97\end{array}$ & $\begin{array}{l}0.45-3.24 \\
2.69-18.1\end{array}$ & $\begin{array}{c}0.72 \\
<0.001\end{array}$ \\
\hline \multicolumn{5}{|l|}{ Tumour differentiation } \\
\hline $\begin{array}{l}\text { Poorly vs well and } \\
\text { moderately }\end{array}$ & $39 / 61$ & 1.94 & $0.90-4.19$ & 0.09 \\
\hline \multicolumn{5}{|l|}{ Primary site } \\
\hline $\begin{array}{l}\text { Jejunum vs duodenum } \\
\text { lleum vs duodenum }\end{array}$ & $\begin{array}{l}39 / 61 \\
39 / 61\end{array}$ & $\begin{array}{l}0.85 \\
1.43\end{array}$ & $\begin{array}{l}0.38-1.86 \\
0.65-3.14\end{array}$ & $\begin{array}{l}0.68 \\
0.37\end{array}$ \\
\hline \multicolumn{5}{|l|}{ Quality of resection } \\
\hline R1 vs R0 & $34 / 56$ & 2.60 & $0.88-7.71$ & 0.08 \\
\hline R2 vs RO & $34 / 56$ & 2.65 & $1.05-6.69$ & 0.04 \\
\hline
\end{tabular}

Table 4. (Continued)

\begin{tabular}{|l|l|l|l|l|}
\hline \multicolumn{4}{|c|}{ Univariate analyses } \\
\cline { 2 - 4 } & \multicolumn{3}{|c|}{$\begin{array}{c}\text { Overall survival } \\
\text { (all patients } n=61)\end{array}$} \\
\cline { 2 - 4 } & Evts/pts & HR & $95 \%$ Cl & P-value $^{\text {a }}$ \\
\hline
\end{tabular}

Baseline CA19-9 (IU ml ${ }^{-1}$ )

\begin{tabular}{|l|c|c|c|c|}
\hline$>37$ vs $\leqslant 37$ & $28 / 34$ & 1.69 & $0.49-5.77$ & 0.40 \\
\hline Baseline CEA $\left(\mathrm{ng} \mathrm{ml}^{-1}\right.$ ) \\
\hline 5 vs $\leqslant 5$ & $33 / 40$ & 0.92 & $0.32-2.65$ & 0.88 \\
\hline$\beta$ P53 & &
\end{tabular}

\begin{tabular}{|l|l|l|l|l|}
\hline Overexpression vs normal & $38 / 60$ & 0.92 & $0.48-1.80$ & 0.82 \\
\hline $\boldsymbol{\beta}$-Catenin
\end{tabular}

\begin{tabular}{|l|c|c|c|c|}
\hline Abnormal vs normal & $38 / 60$ & 0.96 & $0.43-2.11$ & 0.91 \\
\hline MMR phenotype \\
\hline dMMR vs pMMR & $38 / 59$ & 0.29 & $0.10-0.85$ & 0.02 \\
\hline
\end{tabular}

\begin{tabular}{|c|c|c|c|c|}
\hline \multicolumn{5}{|l|}{ KRAS status } \\
\hline Mutated vs wild & $30 / 48$ & 0.72 & 0.35 & 0.36 \\
\hline & \multicolumn{4}{|c|}{ Multivariate analyses } \\
\hline & \multicolumn{4}{|c|}{$\begin{array}{c}\text { Overall survival } \\
\mathbf{N}=35, \text { events }=29 \\
\text { C index }=0.718, \text { likelihood ratio } \\
\text { test }=\mathbf{2 2 . 9 7} \text { for } 4 \mathrm{df}, \mathbf{P}<0.0001\end{array}$} \\
\hline & HR & \multicolumn{2}{|c|}{$95 \% \mathrm{Cl}$} & $P$-value \\
\hline
\end{tabular}

\section{WHO PS}

\begin{tabular}{|c|c|c|c|}
\hline 2 vs $0-1$ & 7.07 & $2.25-22.17$ & $<0.001$ \\
\hline \multicolumn{4}{|l|}{ Disease stage } \\
\hline Stage III vs stages I and II & 0.92 & $0.22-3.89$ & 0.90 \\
\hline Stage IV vs stages I and II & 6.09 & $1.68-22.16$ & $<0.01$ \\
\hline
\end{tabular}

\section{MMR phenotype}

\begin{tabular}{|l|l|l|l}
\hline dMMR vs PMMR & 1.48 & $0.39-5.57$ & 0.56 \\
\hline
\end{tabular}

\begin{tabular}{|c|c|c|c|}
\hline & \multicolumn{3}{|c|}{$\begin{array}{c}\text { Multivariate analyses excluding } \\
\text { PS status }\end{array}$} \\
\hline & \multicolumn{3}{|c|}{$\begin{array}{c}\text { Overall survival } \\
N=57, \text { events }=36 \\
\text { C index }=0.728, \text { likelihood ratio } \\
\text { test }=26.26 \text { for } 3 \mathrm{df}, P<0.0001\end{array}$} \\
\hline & HR & $95 \% \mathrm{Cl}$ & $\boldsymbol{P}$-value \\
\hline \multicolumn{4}{|l|}{ Disease stage } \\
\hline Stage III vs stages I and II & 1.51 & $0.53-4.33$ & 0.44 \\
\hline Stage IV vs stages I and II & 6.78 & $2.57-17.92$ & $<0.001$ \\
\hline \multicolumn{4}{|l|}{ MMR phenotype } \\
\hline dMMR vs pMMR & 0.44 & $0.13-1.55$ & 0.20 \\
\hline \multicolumn{4}{|c|}{$\begin{array}{l}\text { Abbreviations: } C E A=\text { carcinoembryonic antigen; } C \mathrm{Cl}=\text { confidence interval; } \quad \mathrm{dMMR}= \\
\text { mismatch repair deficiency; Evts = events; } \mathrm{HR}=\text { hazard ratio; } \mathrm{pMMR}=\text { proficient mismatch } \\
\text { repair; } \mathrm{PS}=\text { performance status; } \mathrm{pts}=\text { patients; } \mathrm{WHO}=\text { World Health Organisation. } \\
\text { a Log-rank test. }\end{array}$} \\
\hline
\end{tabular}


Table 5. Prognostic factors for patients with stages I-III disease according to recurrence-free survival

Univariate analyses

\begin{tabular}{|c|c|c|c|}
\hline \multicolumn{3}{|c|}{$\begin{array}{c}\text { Recurrence-free survival } \\
\text { (patients with stages I-III } \\
\text { disease and complete } \\
\text { resection, } \boldsymbol{n}=36 \text { ) }\end{array}$} \\
\hline $\begin{array}{c}\text { Evts/ } \\
\text { pts }\end{array}$ & HR & $95 \% \mathrm{Cl}$ & $\boldsymbol{P}$-value \\
\hline
\end{tabular}

Sex

\begin{tabular}{|l|l|l|l|l|}
\hline Male vs female & $17 / 34$ & 1.38 & $0.51-3.74$ & 0.53
\end{tabular}

Age in years

\begin{tabular}{|l|l|l|l|l|}
\hline$>65$ vs $\leqslant 65$ & $17 / 34$ & 0.77 & $0.29-2.0$ & 0.59 \\
\hline
\end{tabular}

WHO PS

\begin{tabular}{|l|l|l|l|l|}
\hline 2 vs $0-1$ & $12 / 14$ & 1.20 & $0.25-5.82$ & 0.82 \\
\hline
\end{tabular}

\section{Disease stage}

Stage III vs stages I and II

\begin{tabular}{|l|l|l|l|}
$17 / 34$ & 0.73 & $0.28-1.90$ & 0.51
\end{tabular}

\section{Tumour differentiation}

\begin{tabular}{|c|c|c|c|c|}
\hline $\begin{array}{l}\text { Poorly vs well and moderately } \\
\text { differentiated }\end{array}$ & $17 / 34$ & 1.3 & $0.39-4.81$ & 0.6 \\
\hline
\end{tabular}

\section{Primary site}

\begin{tabular}{|l|l|l|l|l|}
\hline Jejunum vs duodenum & $17 / 34$ & 1.09 & $0.35-3.34$ & 0.89 \\
Ileum vs duodenum & $17 / 34$ & 1.20 & $0.36-4.01$ & 0.76 \\
\hline
\end{tabular}

Baseline CA19-9 (IU ml ${ }^{-1}$ )

\begin{tabular}{l|l|l|l|l|}
\hline$>37$ vs $\leqslant 37$ & $10 / 11$ & 1.11 & $0.13-9.29$ & 0.93
\end{tabular}

Baseline CEA ( $\mathrm{ng} \mathrm{ml}^{-1}$ )

\begin{tabular}{|c|c|c|c|c|}
\hline$>5 v s \leqslant 5$ & $12 / 14$ & 2.71 & $0.30-24.4$ & 0.37 \\
\hline $\begin{array}{l}\text { Number of invaded lymph nodes for } \\
\text { stage } \text { III }^{\mathbf{b}}\end{array}$ & $17 / 34$ & 1.05 & $0.90-1.23$ & 0.54 \\
\hline $\begin{array}{l}\text { Number of analysed lymph nodes for } \\
\text { stage } \text { III }^{\mathbf{b}}\end{array}$ & $16 / 32$ & 0.98 & $0.91-1.04$ & 0.47 \\
\hline $\begin{array}{l}\text { Ratio of invaded/analysed lymph } \\
\text { nodes for stage } \text { III }^{\mathbf{b}}\end{array}$ & $16 / 32$ & 3.60 & $0.61-21.4$ & 0.16 \\
\hline Adjuvant chemotherapy & & & & \\
\hline No vs yes & $17 / 34$ & 0.89 & $0.31-2.53$ & 0.83 \\
\hline FOLFOX vs $5 \mathrm{U}$ & $12 / 22$ & 0.41 & $0.12-1.38$ & 0.15 \\
\hline
\end{tabular}

P53

\begin{tabular}{|c|c|c|c|c|}
\hline Overexpression vs normal & $17 / 34$ & 1.04 & $0.40-2.70$ & 0.94 \\
\hline \multicolumn{5}{|l|}{$\beta$-Catenin } \\
\hline Abnormal vs normal & $16 / 33$ & 0.92 & $0.30-2.87$ & 0.89 \\
\hline \multicolumn{5}{|l|}{ MMR phenotype } \\
\hline dMMR vs pMMR & $17 / 33$ & 0.41 & $0.13-1.28$ & 0.12 \\
\hline \multicolumn{5}{|l|}{ KRAS status } \\
\hline Mutated vs wild & $11 / 26$ & 0.83 & $0.24-2.84$ & 0.76 \\
\hline \multicolumn{5}{|c|}{$\begin{array}{l}\text { Abbreviations: } \mathrm{Cl}=\text { confidence interval; } \mathrm{dMMR}=\text { mismatch repair deficiency; Evts = events; } \\
\mathrm{HR}=\text { hazard ratio; } \mathrm{pMMR}=\text { proficient mismatch repair; } \mathrm{PS}=\text { performance status; } \\
\text { pts = patients; } \mathrm{WHO}=\text { World Health Organisation. } \\
\text { a Log-rank test. } \\
{ }^{\mathrm{b}} \text { Continuous variable. }\end{array}$} \\
\hline
\end{tabular}

end of follow-up. The median OS was 36.6 months (95\% CI: 26.9; 72.2 months). All the studied variables satisfied the proportional hazards assumption.

In univariate analysis, age, WHO PS, resection quality, stage and dMMR phenotype were significantly associated with OS duration. A trend for poor prognosis was observed in poorly differentiated tumours (Table 4). In multivariate analysis, only stage and WHO PS remained as independent prognostic factors (Table 4). Harrell's $\mathrm{C}$ index was equal to 0.718 . A second model was tested excluding WHO PS due to missing data (Table 4), and the results were similar.

RFS in stages I-III patients. The median follow-up was 63.6 months (95\% CI: 47.8; NA months) and the median RFS was 57.8 months (95\% CI: 42.3; NA months).

No significant prognostic factor of RFS was identified (Table 5). A trend for a worse prognosis was associated with pMMR phenotype and poorly differentiated tumours.

Overall survival in stage IV patients. Thirty-four patients had died after a median follow-up of 69.5 months (95\% CI: 54.1; NA months). The median OS was 20.5 months (95\% CI: 14.6; 36.6 months). In univariate analysis, poor WHO PS, poor differentiation grade, synchronous metastasis and wild-type KRAS were associated with poor prognosis (Table 6). In multivariate analysis, only poor WHO PS and wild-type KRAS were independent factors for poor prognosis (Figure 2).

Table 6. Prognostic factors for metastatic patients according to overall survival

\begin{tabular}{|c|c|c|c|c|}
\hline & \multicolumn{4}{|c|}{ Univariate analyses } \\
\hline & \multicolumn{4}{|c|}{$\begin{array}{c}\text { Overall survival } \\
\text { (metastatic patients } n=41 \text { ) }\end{array}$} \\
\hline & Evts/pts & $\mathrm{HR}$ & $95 \% \mathrm{Cl}$ & $\boldsymbol{P}$-value ${ }^{a}$ \\
\hline \multicolumn{5}{|l|}{ Sex } \\
\hline Female vs male & $34 / 41$ & 1.08 & $0.54-2.17$ & 0.82 \\
\hline \multicolumn{5}{|l|}{ Age in years } \\
\hline $\begin{array}{l}\text { Continuous } \\
>65 \text { vs } \leqslant 65\end{array}$ & $\begin{array}{l}34 / 41 \\
34 / 41\end{array}$ & $\begin{array}{l}0.99 \\
1.17\end{array}$ & $\begin{array}{l}0.97-1.02 \\
0.51-2.63\end{array}$ & $\begin{array}{l}0.64 \\
0.70\end{array}$ \\
\hline \multicolumn{5}{|l|}{ WHO PS } \\
\hline 2 vs $0-1$ & $29 / 34$ & 8.52 & $2.92-24.9$ & $<0.0001$ \\
\hline \multicolumn{5}{|l|}{ Tumour differentiation } \\
\hline $\begin{array}{l}\text { Poorly vs well and moderately } \\
\text { differentiated }\end{array}$ & $34 / 41$ & 2.70 & $1.13-6.46$ & 0.03 \\
\hline \multicolumn{5}{|l|}{ Primary site } \\
\hline $\begin{array}{l}\text { Jejunum vs duodenum } \\
\text { Ileum vs duodenum }\end{array}$ & $\begin{array}{l}34 / 41 \\
34 / 41\end{array}$ & $\begin{array}{l}0.60 \\
1.34\end{array}$ & $\begin{array}{l}0.25-1.40 \\
0.57-3.12\end{array}$ & $\begin{array}{l}0.24 \\
0.50\end{array}$ \\
\hline \multicolumn{5}{|l|}{ Baseline CA19-9 (IU ml $\left.{ }^{-1}\right)$} \\
\hline$>37$ vs $\leqslant 37$ & $25 / 30$ & 2.13 & $0.61-7.37$ & 0.23 \\
\hline \multicolumn{5}{|l|}{ Baseline CEA (ng ml ${ }^{-1}$ ) } \\
\hline$>5$ vs $\leqslant 5$ & $30 / 36$ & 0.84 & $0.29-2.43$ & 0.74 \\
\hline \multicolumn{5}{|l|}{ Palliative chemotherapy } \\
\hline No vs yes & $34 / 41$ & 0.67 & $0.09-5.01$ & 0.69 \\
\hline
\end{tabular}




\begin{tabular}{|c|c|c|c|c|c|}
\hline & \multicolumn{5}{|c|}{ Univariate analyses } \\
\hline & \multicolumn{5}{|c|}{$\begin{array}{c}\text { Overall survival } \\
\text { (metastatic patients } n=41)\end{array}$} \\
\hline & & Evts/pts & $\mathrm{HR}$ & $95 \% \mathrm{Cl}$ & $P$-value ${ }^{\text {a }}$ \\
\hline \multicolumn{6}{|l|}{ Dual therapy } \\
\hline No vs yes & & $33 / 39$ & 4.27 & $0.85-21.6$ & 0.08 \\
\hline \multicolumn{6}{|l|}{ Metastatic } \\
\hline \multicolumn{2}{|l|}{$\begin{array}{l}\text { Synchronous vs } \\
\text { metachronous }\end{array}$} & $34 / 41$ & 2.35 & $1.07-5.19$ & 0.03 \\
\hline \multicolumn{6}{|l|}{ P53 } \\
\hline \multicolumn{2}{|l|}{ Overexpression vs normal } & $33 / 40$ & 0.96 & $0.47-1.95$ & 0.9 \\
\hline \multicolumn{6}{|l|}{$\beta$-Catenin } \\
\hline \multicolumn{2}{|l|}{ Abnormal vs normal } & $34 / 41$ & 1.05 & $0.45-2.43$ & 0.91 \\
\hline \multicolumn{6}{|l|}{ MMR phenotype } \\
\hline \multicolumn{2}{|l|}{ dMMR vs pMMR } & $33 / 40$ & 0.52 & $0.15-1.79$ & 0.30 \\
\hline \multicolumn{6}{|l|}{ KRAS status } \\
\hline \multirow[t]{4}{*}{ Mutated vs wild } & & $26 / 30$ & 0.35 & $0.14-0.83$ & 0.02 \\
\hline & \multicolumn{5}{|c|}{ Multivariate analyses } \\
\hline & \multicolumn{5}{|c|}{$\begin{array}{c}\text { Overall survival } \\
N=26, \text { events }=23 \\
\text { C index }=0.734, \text { likelihood ratio } \\
\text { test }=17.07 \text { for } 2 \mathrm{df}, P<0.001\end{array}$} \\
\hline & HR & & $95 \%$ & & $\boldsymbol{P}$-value \\
\hline \multicolumn{6}{|l|}{ WHO PS } \\
\hline 2 vs $0-1$ & \multicolumn{2}{|l|}{14.6} & \multicolumn{2}{|c|}{$0.19-66.5$} & $<0.001$ \\
\hline \multicolumn{6}{|l|}{ KRAS status } \\
\hline Mutated vs wild & \multicolumn{2}{|c|}{0.37} & \multicolumn{2}{|c|}{$0.15-0.96$} & 0.04 \\
\hline \multicolumn{6}{|c|}{$\begin{array}{l}\text { Abbreviations: } \mathrm{Cl}=\text { confidence interval; } \mathrm{dMMR}=\text { mismatch repair deficiency; Evts = events; } \\
\mathrm{HR}=\text { hazard ratio; } \mathrm{pMMR}=\text { proficient mismatch repair; } \mathrm{PS}=\text { performance status; } \\
\text { pts = patients; } \mathrm{WHO}=\text { World Health Organisation. } \\
{ }^{a} \text { Log-rank test. }\end{array}$} \\
\hline
\end{tabular}

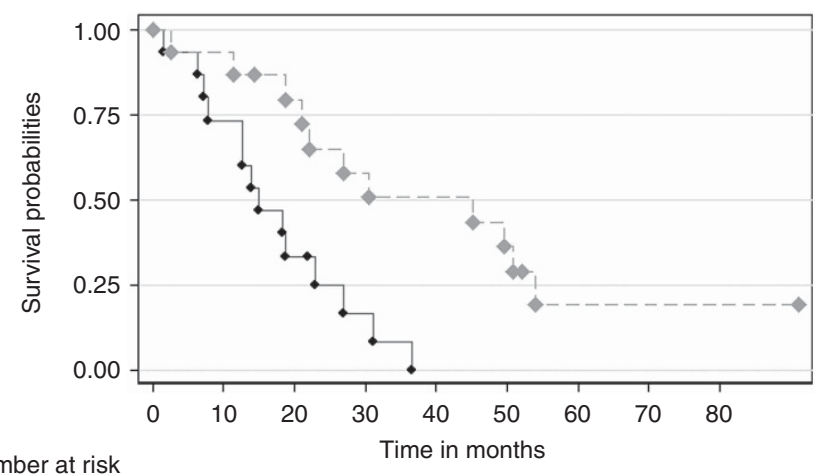

Number at risk

\begin{tabular}{|c|c|c|c|c|c|c|c|c|}
\hline \multirow{3}{*}{$\begin{array}{r}\text { Wild } \\
\text { Mutated }\end{array}$} & 15 & 11 & 5 & 2 & 0 & 0 & 0 & 0 \\
\hline & 15 & 14 & 11 & 8 & 7 & 5 & 2 & 2 \\
\hline & & & & & & $-\leftarrow$ & & \\
\hline
\end{tabular}

Figure 2. Kaplan-Meier survival plot according to KRAS status among patients with stage IV disease.

\section{DISCUSSION}

Our study of 63 cases is one of the largest to consider the clinical and biological characteristics of SBA. We provide molecular and immunophenotypic descriptions of $\mathrm{p} 53, \beta$-catenin, MMR, KRAS, $B R A F$ and HER2, and we have assessed the frequency of abnormalities according to the small bowel segment and assessed the prognostic value of all the clinical and biological characteristics.

The clinical characteristics of the patients enrolled in our study are comparable with those in other large studies on SBA and show that in most cases the primary site is duodenal (Dabaja et al, 2004; Bilimoria et al, 2009; Overman et al, 2012; Aparicio et al, 2013a) and around $20 \%$ of predisposing disease (Aparicio et al, 2013a).

Overexpression of p53 was detected in 26 of 62 cancers (42\%). Ours is the largest study to have determined p53 expression in SBA. Our results are in line with those of Arai et al (1997) and Svrcek et al (2003), who found p53 overexpression in 8 out of $15(53.3 \%)$ and 14 out of $27(40.7 \%)$ cases, respectively, but not those of Wheeler et al (2002), who report an overexpression in 5 of 21 (24\%) SBA cases. Our results support a role of p53 mutation in $40-50 \%$ of SBA cases, as in colorectal or gastric carcinogenesis (Zhang et al, 2006; Bellini et al, 2012). There was no variation of p53 expression according to the small bowel segment or tumour grade. It should be pointed out that p53 overexpression is a rare event in the case of dMMR tumours, as in colorectal carcinogenesis (Olschwang et al, 1997). Surprisingly, p53 overexpression was significantly more frequent in stages I-II tumours than in stage III tumours. This result should be confirmed in a larger number of tumours.

Abnormal accumulation of $\beta$-catenin in the nuclei was observed in 12 of $61(20 \%)$ tumours assessed. In the literature reports, nuclear expression of $\beta$-catenin ranges from 2 out of 27 (7.4\%) (Svrcek et al, 2003), 2 out of 21 (23\%) (Blaker et al, 2004), 79 out of $194(40.7 \%)$ (Lee et al, 2013) to 10 out of 21 (48\%) (Wheeler et al, 2002). One study reported a shorter survival in the case of combined loss of E-cadherin and aberrant $\beta$-catenin expression (Lee et al, 2013). The accumulation of $\beta$-catenin could occur either in the case of APC gene mutation preventing $\beta$-catenin degradation or by gain-of-function mutations (Murata et al, 2000; Blaker et al, 2004). A nuclear accumulation of $\beta$-catenin was observed in the same range of around $20 \%$ of tumours in gastric cancer (Kim et al, 2003). Our results suggest that the Wnt pathway has a much less important role in SBA than in colorectal carcinogenesis in which nuclear accumulation of $\beta$-catenin is seen in around $80 \%$ of tumours (Hao et al, 1997).

We found a KRAS mutation in 21 out of 49 (43\%) tumours, compared with 8 out of 15 (53.3\%) (Arai et al, 1997) and 12 out of 21 (57\%) (Blaker et al, 2004) in literature reports, range of mutation rates similar to that in CRC and higher than in gastric cancer. Nevertheless, two older studies reported KRAS mutation rates of only 5 out of 20 (25\%) (Muneyuki et al, 2000) and 4 out of 28 (14\%) (Younes et al, 1997). The latter study found KRAS mutations only in duodenal tumours, in contrast to our results showing no difference in KRAS mutation rate according to the small intestine segment. A recent large study on resected stages I-III duodenal adenocarcinomas revealed a KRAS mutation rate of $34.6 \%$ and KRAS G>A mutation carriers were at increased risk of distant relapse and had a significantly shorter OS (Fu et al, 2012). Be that as it may, the KRAS mutation rate observed in our study and other studies justifies routine preliminary KRAS determination to identify the patient population in which antiEGFR therapy could be effective.

Reported frequencies of HER2 overexpression in SBA vary widely: 9 out of 16 cases in duodenal tumours in a 1996 study by Zhu et al (1996) and only 1 out of 54 cases in SBA in a recent study (Overman et al, 2010c). The latter result is in line with ours 
showing that HER2 expression is a rare event in SBA. We found no HER2 expression in duodenal tumours, in contrast to the findings Zhu et al (1996), a discrepancy that could be explained by a lack of specificity of the antibody used by these authors. It should be pointed out that in our study the expression of HER2 was confirmed by FISH in the two cases. Moreover, a recent study revealed that genome-wide copy number profiles of most SBAs overlap primarily with colorectal carcinomas rather than gastric adenocarcinomas (Haan et al, 2012). In the study of Haan et al (2012), ERBB2 amplification is a rare event observed in only 1 out of 27 SBA that cluster with colorectal cancer and not gastric cancer.

The frequency of dMMR tumours in SBA reported in the literature ranges from $5 \%$ to $35 \%$ when appropriate methods are applied (Muneyuki et al, 2000; Wheeler et al, 2002; Planck et al, 2003; Svrcek et al, 2003; Brueckl et al, 2004; Zhang et al, 2006; Overman et al, 2010c), probably because of a selection bias in favour of Lynch syndrome patients in the studies with the highest frequency of dMMR tumours. In our study, a dMMR phenotype was observed in 14 out of 61 (23\%) tumours. In a previous study, when Lynch syndrome was excluded, a dMMR was found in only 1 out of 21 (5\%) tumours (Wheeler et al, 2002). In our study, when suspected Lynch syndrome patients were excluded the frequency of dMMR tumours dropped to $9 \%$. In previous studies, the dMMR phenotype was associated with young age (Planck et al, 2003; Overman et al, 2010c). This was not observed in our study. In CRC, the relation between dMMR status and age is complex as young age is associated with Lynch syndrome, but on the other hand advanced age is associated with a high frequency of dMMR tumours due to hypermethylation of the MLH1 promoter (Aparicio et al, 2013b). In the latter case, a BRAF mutation is frequently observed, but in our study only one BRAF mutation was observed in a pMMR tumour. Moreover, MLH1 hypermethylation was infrequent. So, our results suggest that the majority of SBA dMMR tumours are not related to a methylation mechanism but to a germline mutation.

In accordance with the result in CRC (Sargent et al, 2010), dMMR status was associated with an early stage in the present study. A dMMR phenotype was observed more frequently among proximal (duodenum and jejunum) than distal tumours. No dMMR tumour was observed in the ileum. This result was not previously reported and suggests that proximal tumours are more likely due to Lynch syndrome than are distal tumours. Moreover, ileal tumours were related to Crohn's disease in $46 \%$ of the cases. This is in accordance with a previous study on 20 SBAs related to Crohn's disease showing that the tumour occurs mainly in the ileum (Palascak-Juif et al, 2005).

Poor prognosis of SBA is associated with advanced age, pT4 tumour stage, poorly differentiated tumour, positive resection margins, lymphovascular invasion, lymph node invasion and a low number of recovery lymph nodes (Halfdanarson et al, 2010; Nicholl et al, 2010; Overman et al, 2010a). Several large studies suggest that duodenal tumours have a worse prognosis than jejunal or ileal tumours (Howe et al, 1999; Dabaja et al, 2004; Overman et al, 2010a). Similarly to what was reported in a previous study (Overman et al, 2010c), we did not find such a prognostic value of primary site.

Prognostic factors associated with a better overall survival were early tumour stage, R0 resection, WHO PS 0-1 and dMMR tumour in univariate analysis and tumour stage and WHO PS in multivariate analysis. A good prognostic value of dMMR is well documented in colorectal tumours (Sargent et al, 2010). In contrast, a previous study in 54 cases of SBA did not report that MMR status is of prognostic value (Overman et al, 2010c).

In resected tumours, no significant prognostic factors for recurrence were observed. Nevertheless, a trend for a protective effect of $\mathrm{dMMR}$ and well or moderately differentiated tumours was observed. This trend should be studied in a larger number of patients.
In a metastatic setting, the factors predictive of good survival in multivariate analysis were WHO PS $0-1$ and KRAS mutation. This result is in conflict with results in CRC where KRAS mutation had no prognostic value in a metastatic setting (Peeters et al, 2013). It should be pointed out though that none of the patients in our study received an anti-EGFR treatment as first-line chemotherapy.

In conclusion, our results show that SBA has some carcinogenesis pathways in common with CRC. P53 alteration and KRAS mutation are in the same range as in CRC. Nevertheless, some major differences should be pointed out, and the trigger of carcinogenesis seems to be different from that in CRC. A predisposing disease is more frequent than in CRC. The dMMR phenotype frequency appears comparable to that in CRC, but mainly in a context of Lynch syndrome and rarely secondary to HMLH1 promoter methylation, in contrast to CRC. Moreover, the involvement of the Wnt pathway leading to $\beta$-catenin accumulation is less frequent in SBA than in CRC. Moreover, our results suggest that the dMMR phenotype is more frequently observed at an early stage and for duodenal and jejunal adenocarcinoma and had a prognostic value in resected tumours. Surprisingly, KRAS mutation is associated with a good prognosis in a metastatic setting. These results should be confirmed in a larger study. Altogether, our results suggest that SBA should be treated more like CCR than like gastric adenocarcinoma.

\section{ACKNOWLEDGEMENTS}

We thank Professor Sylvie Chevret, URC Saint Louis, Paris, France for data collection. We also thank the pathologists for the samples availability Jean-François Emile (CHU A Paré, Boulogne), Cecile Badoual (CHU Pompidou, Paris), Thierry Lazure (CHU Kremlin Bicêtre), Marie Luce Auriault (CHU H Mondor, Créteil), Jean Christophe Sabourin (CHU Rouen), Serge Guyetant (CHU Tours), Muriel Hourseau (CHU Bichat, Paris), Philippe Bertheau (CHU Saint Louis, Paris), Peggy Dartigues (Institu Gustave Roussy, Villejuif), Francois Kemeny ( $\mathrm{CH}$ Meaux) and Armelle BardierDupas (CHU Pitié-Salpétrière, Paris). This study was supported by grants from the Programme Hospitalier de Recherche Clinique 2009 (AOM 09204). The promoter of this study was the Assistance Public Hôpitaux de Paris, Paris, France.

\section{CONFLICT OF INTEREST}

The authors declare no conflict of interest.

\section{AUTHOR CONTRIBUTIONS}

All authors listed were involved in the conception and design or analysis and interpretation of data and final approval of the version to be published.

\section{REFERENCES}

Aparicio T, Manfredi S, Tougeron D, Bouche O, Pezet D, Mariette C, Coriat R, Zaanan A, Legoux JL, Afchain P (2013a) NADEGE prospective cohort: demographic data of 335 small bowel adenocarcinomas. Eur Cancer Congress Abstract no. 2466. Available at: http://eccamsterdam2013.ecco-org.eu/ Scientific-Programme/Abstract-search.

Aparicio T, Schischmanoff O, Poupardin C, Soufir N, Angelakov C, Barrat C, Levy V, Choudat L, Cucherousset J, Boubaya M, Lagorce C, Guetz GD, Wind P, Benamouzig R (2013b) Deficient mismatch repair phenotype is a prognostic factor for colorectal cancer in elderly patients. Dig Liver Dis 45: 245-250. 
Aparicio T, Zaanan A, Svrcek M, Laurent-Puig P, Carrere N, Manfredi S, Locher C, Afchain P (2013c) Small bowel adenocarcinoma: epidemiology, risk factors, diagnosis and treatment. Dig Liver Dis; e-pub ahead of print 21 June 2013; pii: S1590-8658(13)00184-9; doi:10.1016/j.dld.2013.04.013.

Arai M, Shimizu S, Imai Y, Nakatsuru Y, Oda H, Oohara T, Ishikawa T (1997) Mutations of the Ki-ras, p53 and APC genes in adenocarcinomas of the human small intestine. Int J Cancer 70: 390-395.

Bang YJ, Van Cutsem E, Feyereislova A, Chung HC, Shen L, Sawaki A, Lordick F, Ohtsu A, Omuro Y, Satoh T, Aprile G, Kulikov E, Hill J, Lehle M, Ruschoff J, Kang YK (2010) Trastuzumab in combination with chemotherapy versus chemotherapy alone for treatment of HER2-positive advanced gastric or gastro-oesophageal junction cancer (ToGA): a phase 3 , open-label, randomised controlled trial. Lancet 376: 687-697.

Behrens J (2005) The role of the Wnt signalling pathway in colorectal tumorigenesis. Biochem Soc Trans 33: 672-675.

Bellini MF, Cadamuro AC, Succi M, Proenca MA, Silva AE (2012) Alterations of the TP53 gene in gastric and esophageal carcinogenesis. J Biomed Biotechnol 2012: 891961.

Bilimoria KY, Bentrem DJ, Wayne JD, Ko CY, Bennett CL, Talamonti MS (2009) Small bowel cancer in the United States: changes in epidemiology, treatment, and survival over the last 20 years. Ann Surg 249: 63-71.

Blaker H, Helmchen B, Bonisch A, Aulmann S, Penzel R, Otto HF, Rieker RJ (2004) Mutational activation of the RAS-RAF-MAPK and the Wnt pathway in small intestinal adenocarcinomas. Scand J Gastroenterol 39: 748-753.

Bonadona V, Bonaiti B, Olschwang S, Grandjouan S, Huiart L, Longy M, Guimbaud R, Buecher B, Bignon YJ, Caron O, Colas C, Nogues C, Lejeune-Dumoulin S, Olivier-Faivre L, Polycarpe-Osaer F, Nguyen TD, Desseigne F, Saurin JC, Berthet P, Leroux D, Duffour J, Manouvrier S, Frebourg T, Sobol H, Lasset C, Bonaiti-Pellie C (2011) Cancer risks associated with germline mutations in MLH1, MSH2, and MSH6 genes in Lynch syndrome. JAMA 305: 2304-2310.

Brueckl WM, Heinze E, Milsmann C, Wein A, Koebnick C, Jung A, Croner RS, Brabletz T, Gunther K, Kirchner T, Hahn EG, Hohenberger W, Becker H, Reingruber B (2004) Prognostic significance of microsatellite instability in curatively resected adenocarcinoma of the small intestine. Cancer Lett 203: 181-190.

Dabaja BS, Suki D, Pro B, Bonnen M, Ajani J (2004) Adenocarcinoma of the small bowel: presentation, prognostic factors, and outcome of 217 patients. Cancer 101: 518-526.

Faivre J, Trama A, De Angelis R, Elferink M, Siesling S, Audisio R, Bosset JF, Cervantes A, Lepage C (2012) Incidence, prevalence and survival of patients with rare epithelial digestive cancers diagnosed in Europe in 1995-2002. Eur J Cancer 48: 1417-1424.

Fu T, Guzzetta AA, Jeschke J, Vatapalli R, Dave P, Hooker CM, Morgan R, Iacobuzio-Donahue CA, Liu B, Ahuja N (2012) KRAS G > A mutation favors poor tumor differentiation but may not be associated with prognosis in patients with curatively resected duodenal adenocarcinoma. Int J Cancer 132(11): 2502-2509.

Haan JC, Buffart TE, Eijk PP, van de Wiel MA, van Wieringen WN, Howdle PD, Mulder CJ, van de Velde CJ, Quirke P, Nagtegaal ID, van Grieken NC, Grabsch H, Meijer GA, Ylstra B (2012) Small bowel adenocarcinoma copy number profiles are more closely related to colorectal than to gastric cancers. Ann Oncol 23: 367-374.

Halfdanarson TR, McWilliams RR, Donohue JH, Quevedo JF (2010) A singleinstitution experience with 491 cases of small bowel adenocarcinoma. Am J Surg 199: 797-803.

Hampel H, Frankel WL, Martin E, Arnold M, Khanduja K, Kuebler P, Nakagawa H, Sotamaa K, Prior TW, Westman J, Panescu J, Fix D, Lockman J, Comeras I, de la CA (2005) Screening for the Lynch syndrome (hereditary nonpolyposis colorectal cancer). N Engl J Med 352: 1851-1860.

Hao X, Tomlinson I, Ilyas M, Palazzo JP, Talbot IC (1997) Reciprocity between membranous and nuclear expression of beta-catenin in colorectal tumours. Virchows Arch 431: 167-172.

Howe JR, Karnell LH, Menck HR, Scott-Conner C (1999) The American College of Surgeons Commission on Cancer and the American Cancer Society. Adenocarcinoma of the small bowel: review of the National Cancer Data Base, 1985-1995. Cancer 86: 2693-2706.

Ilyas M, Straub J, Tomlinson IP, Bodmer WF (1999) Genetic pathways in colorectal and other cancers. Eur J Cancer 35: 335-351.

Kim HS, Hong EK, Park SY, Kim WH, Lee HS (2003) Expression of beta-catenin and E-cadherin in the adenoma-carcinoma sequence of the stomach. Anticancer Res 23: 2863-2868.
Koinuma K, Shitoh K, Miyakura Y, Furukawa T, Yamashita Y, Ota J, Ohki R, Choi YL, Wada T, Konishi F, Nagai H, Mano H (2004) Mutations of BRAF are associated with extensive hMLH1 promoter methylation in sporadic colorectal carcinomas. Int J Cancer 108: 237-242.

Kummar S, Ciesielski TE, Fogarasi MC (2002) Management of small bowel adenocarcinoma. Oncology (Williston Park) 16: 1364-1369.

Lee HJ, Lee OJ, Jang KT, Bae YK, Chung JY, Eom DW, Kim JM, Yu E, Hong SM (2013) Combined loss of E-cadherin and aberrant beta-catenin protein expression correlates with a poor prognosis for small intestinal adenocarcinomas. Am J Clin Pathol 139: 167-176.

Lepage C, Bouvier AM, Manfredi S, Dancourt V, Faivre J (2006) Incidence and management of primary malignant small bowel cancers: a welldefined French population study. Am J Gastroenterol 101: 2826-2832.

Lievre A, Bachet JB, Boige V, Cayre A, Le Corre D, Buc E, Ychou M, Bouche O, Landi B, Louvet C, Andre T, Bibeau F, Diebold MD, Rougier P, Ducreux M, Tomasic G, Emile JF, Penault-Llorca F, Laurent-Puig P (2008) KRAS mutations as an independent prognostic factor in patients with advanced colorectal cancer treated with cetuximab. J Clin Oncol 26: 374-379.

Muneyuki T, Watanabe M, Yamanaka M, Isaji S, Kawarada Y, Yatani R (2000) Combination analysis of genetic alterations and cell proliferation in small intestinal carcinomas. Dig Dis Sci 45: 2022-2028.

Murata M, Iwao K, Miyoshi Y, Nagasawa Y, Ohta T, Shibata K, Oda K, Wada H, Tominaga S, Matsuda Y, Ohsawa M, Nakamura Y, Shimano T (2000) Molecular and biological analysis of carcinoma of the small intestine: beta-catenin gene mutation by interstitial deletion involving exon 3 and replication error phenotype. Am J Gastroenterol 95: 1576-1580.

Neugut AI, Jacobson JS, Suh S, Mukherjee R, Arber N (1998) The epidemiology of cancer of the small bowel. Cancer Epidemiol Biomarkers Prev 7: 243-251.

Nicholl MB, Ahuja V, Conway WC, Vu VD, Sim MS, Singh G (2010) Small bowel adenocarcinoma: understaged and undertreated? Ann Surg Oncol 17: 2728-2732.

Olschwang S, Hamelin R, Laurent-Puig P, Thuille B, De Rycke Y, Li YJ, Muzeau F, Girodet J, Salmon RJ, Thomas G (1997) Alternative genetic pathways in colorectal carcinogenesis. Proc Natl Acad Sci USA 94: 12122-12127.

Overman MJ, Hu CY, Kopetz S, Abbruzzese JL, Wolff RA, Chang GJ (2012) A population-based comparison of adenocarcinoma of the large and small intestine: insights into a rare disease. Ann Surg Oncol 19: 1439-1445.

Overman MJ, Hu CY, Wolff RA, Chang GJ (2010a) Prognostic value of lymph node evaluation in small bowel adenocarcinoma: analysis of the surveillance, epidemiology, and end results database. Cancer 116: 5374-5382.

Overman MJ, Kopetz S, Lin E, Abbruzzese JL, Wolff RA (2010b) Is there a role for adjuvant therapy in resected adenocarcinoma of the small intestine. Acta Oncol 49: 474-479.

Overman MJ, Pozadzides J, Kopetz S, Wen S, Abbruzzese JL, Wolff RA, Wang H (2010c) Immunophenotype and molecular characterisation of adenocarcinoma of the small intestine. Br J Cancer 102: 144-150.

Palascak-Juif V, Bouvier AM, Cosnes J, Flourie B, Bouche O, Cadiot G, Lemann M, Bonaz B, Denet C, Marteau P, Gambiez L, Beaugerie L, Faivre J, Carbonnel F (2005) Small bowel adenocarcinoma in patients with Crohn's disease compared with small bowel adenocarcinoma de novo. Inflamm Bowel Dis 11: 828-832.

Park SJ, Rashid A, Lee JH, Kim SG, Hamilton SR, Wu TT (2003) Frequent $\mathrm{CpG}$ island methylation in serrated adenomas of the colorectum. Am J Pathol 162: 815-822.

Peeters M, Douillard JY, Van Cutsem E, Siena S, Zhang K, Williams R, Wiezorek J (2013) Mutant KRAS codon 12 and 13 alleles in patients with metastatic colorectal cancer: assessment as prognostic and predictive biomarkers of response to panitumumab. J Clin Oncol 31: 759-765.

Planck M, Ericson K, Piotrowska Z, Halvarsson B, Rambech E, Nilbert M (2003) Microsatellite instability and expression of MLH1 and MSH2 in carcinomas of the small intestine. Cancer 97: 1551-1557.

Samowitz WS, Curtin K, Ma KN, Edwards S, Schaffer D, Leppert MF, Slattery ML (2002) Prognostic significance of p53 mutations in colon cancer at the population level. Int J Cancer 99: 597-602.

Sargent DJ, Marsoni S, Monges G, Thibodeau SN, Labianca R, Hamilton SR, French AJ, Kabat B, Foster NR, Torri V, Ribic C, Grothey A, Moore M, Zaniboni A, Seitz JF, Sinicrope F, Gallinger S (2010) Defective mismatch 
repair as a predictive marker for lack of efficacy of fluorouracil-based adjuvant therapy in colon cancer. J Clin Oncol 28: 3219-3226.

Svrcek M, Jourdan F, Sebbagh N, Couvelard A, Chatelain D, Mourra N, Olschwang S, Wendum D, Flejou JF (2003) Immunohistochemical analysis of adenocarcinoma of the small intestine: a tissue microarray study. J Clin Pathol 56: 898-903.

Talamonti MS, Goetz LH, Rao S, Joehl RJ (2002) Primary cancers of the small bowel: analysis of prognostic factors and results of surgical management. Arch Surg 137: 564-570.

Wheeler JM, Warren BF, Mortensen NJ, Kim HC, Biddolph SC, Elia G, Beck NE, Williams GT, Shepherd NA, Bateman AC, Bodmer WF (2002) An insight into the genetic pathway of adenocarcinoma of the small intestine. Gut 50: 218-223.

Younes N, Fulton N, Tanaka R, Wayne J, Straus FH, Kaplan EL (1997) The presence of K-12 ras mutations in duodenal adenocarcinomas and the absence of ras mutations in other small bowel adenocarcinomas and carcinoid tumors. Cancer 79: 1804-1808.

Zaanan A, Costes L, Gauthier M, Malka D, Locher C, Mitry E, Tougeron D, Lecomte T, Gornet JM, Sobhani I, Moulin V, Afchain P, Taieb J, Bonnetain F, Aparicio T (2010) Chemotherapy of advanced small-bowel adenocarcinoma: a multicenter AGEO study. Ann Oncol 21: $1786-1793$.
Zaanan A, Gauthier M, Malka D, Locher C, Gornet JM, Thirot-Bidault A, Tougeron D, Taieb J, Bonnetain F, Aparicio T (2011a) Second-line chemotherapy with fluorouracil, leucovorin, and irinotecan (FOLFIRI regimen) in patients with advanced small bowel adenocarcinoma after failure of first-line platinum-based chemotherapy: a multicenter AGEO study. Cancer 117: 1422-1428.

Zaanan A, Meunier K, Sangar F, Flejou JF, Praz F (2011b) Microsatellite instability in colorectal cancer: from molecular oncogenic mechanisms to clinical implications. Cell Oncol (Dordr) 34: 155-176.

Zhang MQ, Chen ZM, Wang HL (2006) Immunohistochemical investigation of tumorigenic pathways in small intestinal adenocarcinoma: a comparison with colorectal adenocarcinoma. Mod Pathol 19: 573-580.

Zhu L, Kim K, Domenico DR, Appert HE, Howard JM (1996) Adenocarcinoma of duodenum and ampulla of Vater: clinicopathology study and expression of p53, c-neu, TGF-alpha, CEA, and EMA. J Surg Oncol 61: 100-105.

This work is published under the standard license to publish agreement. After 12 months the work will become freely available and the license terms will switch to a Creative Commons AttributionNonCommercial-Share Alike 3.0 Unported License. 